\title{
Development of healthy and sustainable food-based dietary guidelines for the Netherlands
}

\author{
Elizabeth Brink ${ }^{1} *$, Caroline van Rossum ${ }^{2}$, Astrid Postma-Smeets ${ }^{1}$, Annette Stafleu ${ }^{1}$, \\ Danielle Wolvers ${ }^{1}$, Corné van Dooren 1 , Ido Toxopeus², Elly Buurma-Rethans², \\ Marjolein Geurts ${ }^{2}$ and Marga Ocké ${ }^{2}$ \\ 'The Netherlands Nutrition Centre (Voedingscentrum), PO Box 85700, 2508 CK The Hague, The Netherlands: \\ ${ }^{2}$ National Institute for Public Health and the Environment (RIVM), Bilthoven, The Netherlands
}

Submitted 13 July 2018: Final revision received 4 March 2019: Accepted 27 March 2019: First published online 2 July 2019

\begin{abstract}
Objective: To derive healthy and sustainable food-based dietary guidelines (FBDG) for different target groups in the Netherlands and describe the process. Design: Optimised dietary patterns for children, adolescents, adults and the elderly were calculated using an optimisation model. Foods high in saturated and trans-fatty acids, salt and sugar, and low in dietary fibre, were excluded. The dietary patterns resembled the current food consumption as closely as possible, while simultaneously meeting recommendations for food groups, nutrients, maximum limits for foods with a high environmental impact, and within $85 \%$ of the energy requirement. Recommended daily amounts of food groups were based on the optimised dietary patterns and expert judgement.

Setting: The Netherlands.

Participants: FBDG were derived for Dutch people with different ages, genders, activity levels and food preferences.

Results: For most target groups the optimisation model provided dietary patterns that complied with all requirements. For some food groups, the optimised amounts varied largely between target groups. For consistent messages to consumers, the optimised dietary patterns were adjusted to uniform recommendations per target group. Recommendations were visualised in the Wheel of Five. The advice is to eat the recommended amounts of foods according to the Wheel of Five and limit consumption of other foods.

Conclusions: Based on an optimisation model, scientific evidence, information on dietary patterns and expert knowledge, we derived FBDG for different target groups. The Wheel of Five is a key food-counselling model that can help Dutch consumers to make their diets healthier and more environmentally sustainable.
\end{abstract}

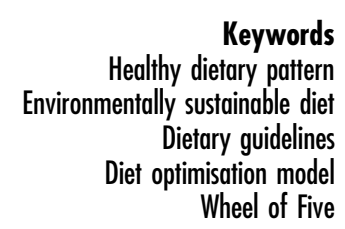

Healthy dietary habits are important for maintaining good health and preventing diet-related chronic diseases ${ }^{(1)}$. Strategies to promote a healthy diet include the development of food-based dietary guidelines (FBDG). FBDG provide advice to the general public on foods, food groups and dietary patterns to provide the required nutrients, prevent chronic diseases and promote overall health while considering culture-specific food preferences ${ }^{(2,3)}$. The methods to develop FBDG differ between countries ${ }^{(4)}$ and have changed over time. More recently, awareness has grown that through adaptations of the daily diet, the environmental impact, like greenhouse gas emissions (GHGE), can be substantially reduced ${ }^{(5)}$. The environmental impact of the diet has been taken into account in some FBDG $^{(6-8)}$.

In 1998, the FAO and WHO published the key scientific considerations for the derivation of $\mathrm{FBDG}^{(9)}$. In 2010, these were further specified by the European Food Safety Authority, which advised a stepwise approach that starts with the assessment of relationships between diet and health and ends with graphical representations of FBDG. An important component of the European Food Safety Authority's approach is testing and optimising FBDG ${ }^{(2)}$. Initially, testing and optimising FBDG was done in an iterative process whereby recommended portions of food groups were modified by experts, using trial and error, until 


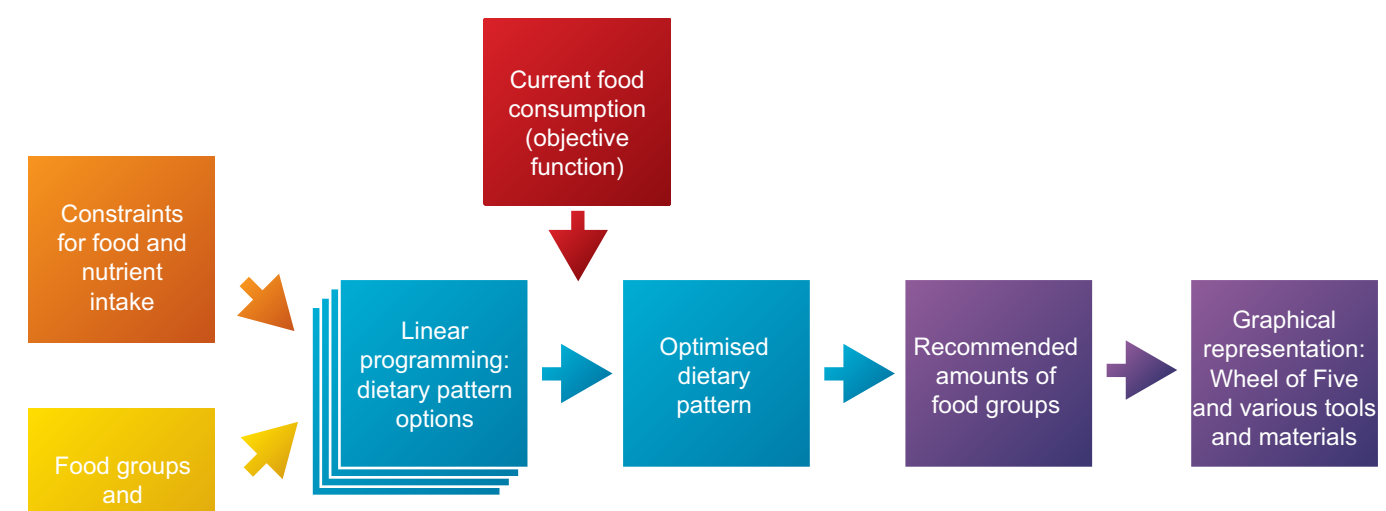

Advice from scientists and dietitians, input from consumers

Fig. 1 Overview of the development process for food-based dietary guidelines for the general Dutch population (○९, input; $\bullet$, calculations; $\bullet$, recommendations)

the dietary pattern satisfied the selected constraints ${ }^{(10-12)}$. Constraints could be based, among other things, on nutrient recommendations, current food consumption patterns of the relevant population and cultural factors. In recent years, several countries have used computerised diet optimisation models $^{(13-15)}$ to decrease subjective decision making ${ }^{(16,17)}$ and to improve the fulfilment of the nutrient recommendations ${ }^{(15)}$. Diet optimisation is a mathematical approach that determines the optimal diet given a certain objective function and a set of constraints. In the optimal diet, all constraints are simultaneously achieved if the model provides a solution ${ }^{(18)}$. These constraints are usually intake ranges for nutrients, defined by RDA and safe upper intake levels. The objective function for the optimal diet is often minimising adjustments to the average diet of the target population ${ }^{(13,15)}$ but can also be the lowest environmental impact, price or energetic value $e^{(17,19)}$.

The Health Council of the Netherlands (HCNL) derived dietary guidelines based on twenty-nine systematic reviews that summarised randomised controlled trials, prospective cohort studies on nutrients, foods and dietary patterns, and the risk of the top ten major chronic diseases in the Netherlands. Dietary guidelines were formulated for foods and food patterns that lead to health gains, for those food groups for which there was convincing or plausible evidence ${ }^{(20)}$. Therefore, following the guidelines may provide one with dietary patterns lacking energy and sufficient essential nutrients. Moreover, some of the guidelines were rather broad and did not specify quantities, such as "Eat legumes weekly' and 'Replace refined cereal products with wholegrain products'. In a follow-up process, the Netherlands Nutrition Centre and the National Institute for Public Health and the Environment derived FBDG. In this process, simultaneously the Dutch dietary guidelines ${ }^{(20)}$, the Dietary Reference Values (DRV) $)^{(21)}$ and current Dutch consumption patterns ${ }^{(22-25)}$ were taken into account in an optimisation model, and combined with expert judgement.

The aim of the present paper is to describe the process and choices made when deriving the FBDG for the Netherlands and its results: practical recommendations for healthy dietary patterns for different target groups, taking into account aspects of environmental impact of specific foods, visualised in the Wheel of Five.

\section{Methods}

Figure 1 presents a schematic overview of the development process for the FBDG for the Netherlands. We used a dual approach involving calculations and expert judgement. We used a mathematical approach to calculate an optimised dietary pattern for several subgroups among the population, given a set of constraints and objective functions. Constraints were set for food groups based on health effects as described by $\mathrm{HCNL}^{(20)}$, considerations with respect to environmental impact in accordance with HCNL guidelines $^{(20,26)}$ and feasibility based on food consumption data $^{(22-24)}$. Minimum and maximum constraints for nutrients and energy were based on the DRV ${ }^{(21)}$ and tolerable upper intake levels ${ }^{(27)}$. The optimised dietary pattern was the pattern closest to the current diet (objective function) ${ }^{(22-25)}$. The results of this approach were translated into FBDG, including a visualisation in the form of the Wheel of Five, web applications and educational materials. External experts representing various disciplines in nutrition science were involved throughout the process, starting with an evaluation of the 2011 FBDG for the Netherlands ${ }^{(10)}$. Additionally, dietitians and consumer groups were consulted for advice and testing concepts. 
Table 1 Food group classification and criteria to include or exclude specific foods in or from the Wheel of Five (see Brink et al. ${ }^{(38)}$ for detailed information) ${ }^{*}, \dagger$

\begin{tabular}{|c|c|c|c|c|c|c|}
\hline \multirow[b]{2}{*}{ Food group } & \multicolumn{5}{|c|}{ Nutrients for which criteria were set } & \multirow[b]{2}{*}{ Additional criteria } \\
\hline & SFA & TFA & Sodium & $\begin{array}{c}\text { Sugar } \\
\text { (added/total) }\end{array}$ & Fibre & \\
\hline Vegetables $\ddagger$ & $x$ & $x$ & $x$ & $x$ & & No drinks \\
\hline Fruitł & $x$ & $x$ & $x$ & $x$ & & No drinks \\
\hline Potatoes $\ddagger$ & $x$ & $x$ & $x$ & $x$ & & \\
\hline Bread & $x$ & $x$ & $x$ & $x$ & $\mathrm{x}$ & \\
\hline Cereal products (no bread) & $x$ & $x$ & $x$ & $x$ & $x$ & \\
\hline Legumes $\ddagger$ & $x$ & $x$ & $x$ & $x$ & & \\
\hline Nutsł & $x$ & $x$ & $x$ & $x$ & & \\
\hline White meat and meat replacements & $x$ & $x$ & $x$ & $x$ & & $\begin{array}{l}\text { Iron, vitamin } \mathrm{B}_{12} \text { or thiamin, protein } \\
\text { for meat replacements }\end{array}$ \\
\hline Red meat & $x$ & $x$ & $x$ & $\mathrm{x}$ & & \\
\hline Milk (products) and milk substitutes & $x$ & $x$ & $x$ & $x$ & & $\begin{array}{l}\text { Calcium, vitamin } B_{12} \text {, protein for milk } \\
\text { substitutes }\end{array}$ \\
\hline Cheese and cheese substitutes & $x$ & $x$ & $x$ & $x$ & & $\begin{array}{l}\text { Calcium, vitamin } B_{12} \text {, protein for } \\
\text { cheese substitutes }\end{array}$ \\
\hline $\begin{array}{l}\text { Oils, fats and spreads } \\
\text { Non-alcoholic beverages }\end{array}$ & $x$ & $x$ & $x$ & $x$ & & $\begin{array}{l}\text { Only water, tea, coffee without sugar } \\
\text { are in the Wheel of Five }\end{array}$ \\
\hline
\end{tabular}

TFA, trans-fatty acids.

${ }^{*}$ Food groups fully placed inside the Wheel of Five: fish, eggs. Fish products should consist of at least $70 \%$ fish.

†Food groups fully placed outside the Wheel of Five: processed meat, cold cuts, alcoholic beverages, ready-to-eat meals, sandwiches, soups, sauces, savoury snacks, sweet snacks, savoury bread spreads, sweet bread spreads, miscellaneous.

$\ddagger$ Subdivision in unprocessed and processed.

\section{Target population groups for the food-based dietary guidelines}

The FBDG for the Netherlands were developed for various subgroups among the population that differ in energy and nutrient requirements or dietary habits. First, optimised dietary patterns and subsequently FBDG were derived by gender for the age groups of $1-3,4-8,9-13,14-18$, 19-30, 31-50, 51-69 and $\geq 70$ years. Consecutively, FBDG were derived for pregnant and lactating women, for subgroups with a higher activity level, no meat consumption and more non-Western food choices as used by people with Turkish, Moroccan and Surinamese backgrounds living in the Netherlands ${ }^{(25)}$. The FBDG were developed for apparently healthy people with a BMI between 18 and $25 \mathrm{~kg} / \mathrm{m}^{2}$. For people with underweight, obesity or having a specific disease, individual advice is required by a dietitian who takes account of the individual situation and risks. The FBDG serve as starting point for these advices.

\section{Food groups for the food-based dietary guidelines}

The food groups included in the Wheel of Five were those mentioned in HCNL's dietary guidelines ${ }^{(20)}$ as being associated with a reduced risk for chronic diseases such as CHD or cancer, like vegetables or wholegrain products, and those that are nutrient-dense and contain essential nutrients ${ }^{(28)}$. Food groups for which HCNL strongly recommends that their consumption be substantially limited or as low as possible were excluded entirely. Examples of such food groups are processed meat and sugary beverages. For other food groups, foods that contain too many nutrients with adverse health effects (SFA, trans-fatty acids (TFA), sugar or salt) or too little dietary fibre were excluded from the Wheel of Five. To this end, maximum levels were set for SFA, TFA, sodium and sugar (monosaccharides and disaccharides) and minimum levels for dietary fibre. Per food group, the appropriate levels were established based on the nutrient content ${ }^{(28)}$, the health effect ${ }^{(20,21)}$, the degree of processing, food-group-specific considerations $^{(29,30)}$ and sufficient choice options for consumers ${ }^{(28)}$. The final criteria were reviewed by independent experts not involved in the food industry. As a result of the criteria, parts of some food groups were excluded from the Wheel of Five and the optimisation calculations. For example, refined-grain products were excluded from the cereal group. For foods that were excluded from the Wheel of Five additional recommendations were developed (see below). An overview of the foods and whether or not they were included in the Wheel of Five is shown in Table 1.

\section{Optimisation calculations}

\section{Constraints}

The basic principles were that recommended amounts of foods in the Wheel of Five deliver $100 \%$ of the essential nutrients and that limited consumption of foods that are excluded from the Wheel of Five is allowed. The first principle could be realised when about $85 \%$ of the total energy was provided by foods in the Wheel of Five. The constraint for energy was therefore set at $85 \%$ of the energy requirement. The energy requirement was the Estimated Average Requirement for individuals with an inactive lifestyle, in 
Table 2 List of food constraints for adults used in the optimisation calculations in the development of food-based dietary guidelines for the Netherlands

\begin{tabular}{|c|c|c|c|c|}
\hline Food group & Minimum & Reason for minimum & Maximum & Reason for maximum \\
\hline Vegetables $(\mathrm{g} / \mathrm{d})$ & 200 & Health* & - & \\
\hline Fruit $(g / d)$ & 200 & Health* & - & \\
\hline Wholegrain cereals $(\mathrm{g} / \mathrm{d})$ & 90 & Health* & - & \\
\hline Fish (g/week) & 100 & Health $†$ & 125 & Environmental impact $\|$ \\
\hline Legumes (g/week) & 65 & Health $\dagger$ & 135 & Feasibility§ \\
\hline Red meat (g/week) & - & & $\begin{array}{c}\text { Male: } 500 \dagger, \ddagger \\
\text { Female: } 50 \text { th percentile of consumption§ }\end{array}$ & Health†, environmental impact $\|$ \\
\hline Total meat (g/week) & - & & 50th percentile of consumption§ & Environmental impact || \\
\hline Eggs (g/week) & - & & 150 & Health†, environmental impact $\|$ \\
\hline Nuts $(g / d)$ & 15 & Health* & 25 & Feasibility§ \\
\hline Dairy products (g/d) & 300 & Health $\dagger$ & 75th percentile of consumption§ & Environmental impact\| \\
\hline
\end{tabular}

${ }^{*}$ Quantitative guideline of the Health Council of the Netherlands ${ }^{(20)}$.

†Translation of qualitative guideline of the Health Council of the Netherlands ${ }^{(20,38)}$

†Recommendation of the World Cancer Research Fund(40).

§Dutch National Food Consumption Survey (22).

$\|$ Based on guidelines of the Health Council of the Netherlands ${ }^{(20,26)}$.

order to prevent overconsumption and overweight ${ }^{(31)}$. For adults, the Estimated Average Requirements were calculated based on BMR and a physical activity level ${ }^{(31)}$ of 1.4 for women and 1.5 for men ${ }^{(32)}$. Average weights for BMR estimations were obtained from the Public Health Monitor 2014. The corresponding BMI values were $23.2 \mathrm{~kg} / \mathrm{m}^{2}$ for men and $22.4 \mathrm{~kg} / \mathrm{m}^{2}$ for women. The energy requirements for children were based on Dutch growth diagrams ${ }^{(33,34)}$ and literature ${ }^{(35-37)}$.

In addition, minimum and maximum constraints for daily intakes of foods (Table 2) and nutrients (Table 3) were defined. An extensive description of the choices made and the rationale is given by Brink et al. ${ }^{(38)}$.

Minimum constraints were set for vegetables, fruit, wholegrain products, unsalted nuts, legumes, dairy products and fish because HCNL showed that consumption of these products is associated with a reduced risk for chronic diseases ${ }^{(20)}$. For vegetables, fruits, wholegrain products and unsalted nuts, HCNL derived quantitative guidelines such as 'Eat at least $15 \mathrm{~g}$ of nuts daily'. These quantities were set as minimum constraints for the specific food groups. For dairy products, fish and legumes, HCNL derived qualitative guidelines. These were translated to minimum constraints taking into account serving sizes and/or current consumption ${ }^{(22)}$, or nutrient provision ${ }^{(28)}$. The HCNL guideline 'Take a few portions of dairy products daily, including milk or yoghurt' was translated into a minimum constraint of $300 \mathrm{~g}$, given a serving size of $150 \mathrm{~g}$ and the additional HCNL recommendation to maintain the current consumption, which is on average about $300 \mathrm{~g} / \mathrm{d}^{(22)}$. For fish the minimum constraint was the serving size of $100 \mathrm{~g}$. For legumes the minimum was the amount that delivers the same amount of iron as one serving of meat ${ }^{(28)}$.

Additionally, for unsalted nuts, legumes, total meat and red meat, eggs, fish and dairy products, maximum constraints were set. Reasons were a low current consumption (nuts and legumes) ${ }^{(22)}$, a high consumption being associated with increased risk for chronic diseases (eggs and red meat $)^{(20)}$ and a limitation of consumption of animal foods because of environmental aspects (meat, red meat, dairy products, eggs, fish) ${ }^{(20,26,39)}$. For nuts a maximum level was set as the amount that provides the same amount of iron as one serving of meat ${ }^{(28)}$, and for legumes as the amount that is eaten by users on consumption days ${ }^{(22)}$. For eggs, HCNL indicates that a more than average consumption of cholesterol-rich products is not desirable ${ }^{(20)}$. The maximum level for eggs was set at the current consumption $^{(22)}$. For meat and red meat we ambitiously set a maximum level at the 50th percentile of the current consumption $^{(22)}$ in order to limit the consumption of animal products with high GHGE. However, for men the 50th percentile for red meat was over $700 \mathrm{~g} /$ week, whereas the World Cancer and Research Fund recommends a maximum of $500 \mathrm{~g} /$ week, because high consumption of red meat is associated with increased risk for colon cancer ${ }^{(40)}$. Therefore, this was set as the maximum constraint for men. For dairy products the 50th percentile of the current consumption is meeting the guideline of HCNL, which is associated with a reduced risk for colon cancer ${ }^{(20,22)}$. Additionally, dairy products are important sources of essential nutrients for which the current consumption for some groups lower is than the DRV (like calcium, potassium and vitamin $\mathrm{A})^{(22,28)}$. We therefore chose the 75 th percentile of the current consumption as a maximum level. For fish, finally, it was shown that more than one portion of fish per week does not add to reduction of disease risk ${ }^{(20)}$ whereas it does have environmental impact. We chose a maximum taking into account one big serving of $125 \mathrm{~g}$.

The food group constraints for adults are shown in Table 2. For children, the minimum levels for some food groups were extrapolated to lower amounts. The starting point was $75 \%$ of the amount for the $9-13$ years age group, $50 \%$ for the $4-8$ years age group and $25 \%$ for the $1-3$ years age group. This applied to vegetables, fish and legumes. For fruits and wholegrain products, other percentages were 
Table 3 List of constraints for energy and nutrients used in the optimisation calculations in the development of food-based dietary guidelines for the Netherlands

\begin{tabular}{|c|c|c|c|c|}
\hline Nutrient or energy & Minimum & Reason for minimum & Maximum & Reason for maximum \\
\hline Energy & $\begin{array}{l}85 \% \text { of the EAR for } \\
\text { inactive persons }{ }^{*}\end{array}$ & Health & $\begin{array}{l}85 \% \text { of the EAR for } \\
\text { inactive persons* }\end{array}$ & Health \\
\hline $\begin{array}{l}\text { Macronutrients } \\
\text { Total fat } \\
\text { Total protein } \\
\text { Total carbohydrates }\end{array}$ & $\begin{array}{l}\text { Lower value of } \\
\text { recommended range† }\end{array}$ & Health & $\begin{array}{l}\text { Higher value of } \\
\text { recommended range } \dagger\end{array}$ & Health \\
\hline $\begin{array}{l}\text { Fatty acids with maximum intake } \\
\text { Trans-fatty acids } \\
\text { SFA }\end{array}$ & - & - & $\begin{array}{l}\text { Recommended } \\
\text { maximum intake† }\end{array}$ & Health \\
\hline $\begin{array}{l}\text { Fatty acids and dietary fibre } \\
\text { MUFA } \\
\alpha \text {-Linolenic acid } \\
\text { Linoleic acid } \\
\text { DHA } \\
\text { EPA } \\
\text { Dietary fibre }\end{array}$ & Recommended intake & Health & - & - \\
\hline $\begin{array}{l}\text { Nutrients with Al and UL } \\
\text { Calcium } \\
\text { Zinc } \\
\text { Selenium } \\
\text { Copper } \\
\text { lodine } \\
\text { Retinol } \\
\text { Vitamin } \mathrm{B}_{6} \\
\text { Vitamin D } \\
\text { Vitamin E }\end{array}$ & $\mathrm{Al}$ or RDI† & Health & UL‡ & Food safety \\
\hline $\begin{array}{l}\text { Nutrients without UL } \\
\text { Phosphorus } \\
\text { Iron } \\
\text { Potassium } \\
\text { Magnesium } \\
\text { Thiamin } \\
\text { Riboflavin } \\
\text { Vitamin } \mathrm{B}_{12} \\
\text { Vitamin C } \\
\text { Folate equivalents } \\
\text { Nicotinic acid } \\
\text { Retinol activity equivalents } \\
\text { Vitamin K }\end{array}$ & $\mathrm{Al}$ or RDI† & Health & - & - \\
\hline $\begin{array}{l}\text { Other nutrients with maximum intake } \\
\text { Folic acid }\end{array}$ & - & - & UL‡ & Food safety \\
\hline Sodium & - & - & $\begin{array}{l}\text { Recommended } \\
\text { maximum intake§ }\end{array}$ & Health \\
\hline Alcohol & - & - & $\begin{array}{l}\text { Recommended } \\
\text { (maximum) intake§ }\end{array}$ & Health \\
\hline
\end{tabular}

AI, Adequate Intake; UL, safe upper level; EAR, Estimated Average Requirement; RDI, Recommended Dietary Intake; DRV, Dietary Reference Value.

Detailed information on constraints is available in the online supplementary material, Supplemental Table S1.

*Energy intake recommended by Health Council of the Netherlands is the EAR in order to prevent overconsumption and undesirable weight gain ${ }^{(31)}$. Physical activity level value for inactive persons is 1.4 for women and 1.5 for men $^{(32)}$.

tHealth Council of the Netherlands' DRV(21). DRV are given as either RDI or Al, which have the same application.

fUL of the European Food Safety Authority(27).

§Dietary guidelines of the Health Council of the Netherlands ${ }^{(20)}$.

used. For nuts and dairy products, the same minimum levels were used for children and adults. More detailed information on the levels and rationale is available ${ }^{(38)}$.

Constraints for nutrients were based on HCNL's DRV ${ }^{(20)}$ and the European Food Safety Authority's tolerable upper intake levels ${ }^{(27)}$. The minimum level was set at the level of the recommended intake or adequate intake. The minimum level for vitamin D was set at $3 \mu \mathrm{g} / \mathrm{d}$, assuming that the rest of the required vitamin $\mathrm{D}$ was synthesised in the skin or obtained by dietary supplements ${ }^{(41)}$. The tolerable upper intake level, if applicable, was set as the maximum level. Recommendations for macronutrients were given as a range related to the energy intake ${ }^{(31)}$. For macronutrients, the minimum and maximum levels were based on respectively the lower and upper value of the recommended range. The constraints for nutrients are shown in Table 3 and the online supplementary material, Supplemental Table S1. 


\section{Nutrient composition of the food groups}

The food groups included in the optimisation calculations were those that were part of the Wheel of Five (Table 1). The nutrient and energy contents of each food group were calculated. This was a weighted average of the nutrient values of all currently consumed foods per food group. This information was obtained from the results of the Dutch National Food Consumption Surveys ${ }^{(22-24)}$, which were combined with an extended version of the Dutch Food Composition Database $2013^{(28)}$. Because the optimised diet should be achievable without choosing fortified products, fortified foods were excluded, except for products for which the Netherlands had made special arrangements with producers. These included products with iodised bakers' salt and margarines and products used for baking and frying fortified with vitamin A and vitamin D. Additionally, fortified meat substitutes (iron, thiamin, vitamin $\mathrm{B}_{12}$ ) and dairy substitutes (calcium, vitamin $\mathrm{B}_{12}$ ) were included. The weighted mean composition was calculated for five age groups: $1-3,4-8,9-18,19-69$ and $\geq 70$ years, without sex distinction.

\section{Optimisation model}

The optimisation calculations were performed with the optimisation model Optimeal ${ }^{\circledR}$ (www.optimeal.info) ${ }^{(42,43)}$, which was modified for this purpose. For each target group, a dietary pattern was generated that complied with the constraints and was as close as possible to the current diet (objective function) for reasons of cultural acceptability. 'As close as possible' is defined as minimising the sum of the squared differences (quadratic function) in food group amounts (grams) of the optimised diet and the consumption in the Dutch National Food Consumption Surveys ${ }^{(22-24)}$. A quadratic function was chosen rather than an ordinary linear function to give preference to small changes in more food groups over a large change in one food group; for example, a preference for $20 \mathrm{~g}$ difference in three food groups (sum of squared differences $=3 \times 20^{2}=1200$ ), rather than a difference of $60 \mathrm{~g}$ in one food group (squared difference $=3600$ ). This approach is in line with our recommendations to improve a dietary pattern by small steps, and not by suddenly introducing major changes.

\section{Deriving recommended daily amounts for food groups}

In order to be able to send consistent messages to consumers, the optimised dietary patterns in grams were converted into recommended daily amounts for food groups in practical quantities and serving sizes for the various target groups. This was done in an iterative process based on expert judgement and took account of the constraints and results of the optimisation calculations and serving size. The result was a recommended dietary pattern for each target group. The nutrient provision was checked for all recommended dietary patterns. If not all DRV for nutrients were met, some adaptions in recommended amounts were made, or specific points of attention for consumer advice were defined.

Feasibility, environmental impact and consistency between the various target groups were also considered. In case that the optimisation calculations yielded no solution, the recommendations were extrapolated from the recommendations for other groups, taking into account their energy and nutrient requirements ${ }^{(21)}$ and current consumption $^{(22,24)}$. Particularly the steps for deriving recommended daily amounts were discussed in expert sessions. The (understanding of the) resulting set of recommendations was tested among dietitians and consumers.

\section{Approach for target groups with higher energy requirements and different food preferences}

Higher energy requirements. For pregnant and breastfeeding women, no recent food consumption data were available. Therefore, the recommendations were based on those for women aged 19-50 years. As pregnant and breast-feeding women have higher nutrient and energy requirements ${ }^{(21)}$, additional recommendations for foods were derived by experts to meet these requirements. These were based on the habitual dietary pattern of this ${\text { age } \text { group }^{(22)} \text { and food composition data }}^{(28)}$.

The recommended food amounts were set for an inactive population with a physical activity level value of 1.5 and 1.4 for men and women, respectively ${ }^{(32)}$. A physical activity level value of 1.7 was used for more active persons ${ }^{(32)}$, resulting in a higher energy requirement. General recommendations were formulated to meet these extra energy requirements on top of the derived recommended daily amounts for foods.

No meat. In order to give practical recommendations to those who prefer to omit meat from their diet, a recommended dietary pattern without meat, but including fish, was derived for all above-mentioned target groups. The basic principle was to replace the recommended amounts of meat with a combination of legumes, nuts and eggs. This was done in a similar way to the iterative process described above.

Non-Western dietary patterns. Part of the Dutch population consists of non-Western migrants. The three main groups are people with a Turkish, Moroccan and Surinamese background ${ }^{(44)}$. It was evaluated whether recommendations for the general population were applicable to these groups. Optimisation calculations were performed as described above with some adaptations ${ }^{(38)}$ : constraints were adapted to lower energy requirements because of their shorter average height ${ }^{(25)}$ and to recommended amounts for foods for the general Dutch population. Additionally, constraints for some nutrients were excluded for women. Food group composition and current consumption were based on food consumption data for non-Western groups ${ }^{(25)}$. It was evaluated whether the results of the optimisation calculations corresponded with 
Table 4 Results of the optimisation calculations for the Dutch food pattern per age and gender. Data are presented as grams per day*

\begin{tabular}{|c|c|c|c|c|c|c|c|c|c|c|c|}
\hline \multirow[b]{2}{*}{ Food group } & \multicolumn{2}{|c|}{$9-13$ years } & \multirow{2}{*}{$\frac{14-18 \text { years }}{M}$} & \multicolumn{2}{|c|}{$19-30$ years } & \multicolumn{2}{|c|}{$31-50$ years } & \multicolumn{2}{|c|}{$51-69$ years } & \multicolumn{2}{|c|}{$\geq 70$ years } \\
\hline & M & $\mathrm{F}$ & & M & $\mathrm{F}$ & $M$ & $\mathrm{~F}$ & M & $\mathrm{F}$ & M & $\mathrm{F}$ \\
\hline Vegetables & 272 & 389 & 234 & 200 & 561 & 204 & 700 & 246 & 249 & 235 & 271 \\
\hline Fruit & 200 & 200 & 200 & 200 & 200 & 200 & 200 & 200 & 200 & 200 & 200 \\
\hline Bread & 214 & 260 & 254 & 275 & 334 & 271 & 245 & 232 & 136 & 195 & 113 \\
\hline Cereal products & 81 & 0 & 221 & 200 & 9 & 169 & 75 & 125 & 76 & 82 & 132 \\
\hline Potatoes & 163 & 140 & 193 & 147 & 26 & 137 & 0 & 133 & 93 & 127 & 37 \\
\hline Fish and shellfish & 18 & 18 & 16 & 15 & 18 & 16 & 18 & 18 & 18 & 18 & 18 \\
\hline Lequmes & 19 & 19 & 19 & 19 & 19 & 19 & 19 & 19 & 19 & 19 & 9 \\
\hline Poultry & 43 & 63 & 32 & 31 & 68 & 11 & 68 & 22 & 13 & 30 & 19 \\
\hline Red meat & 46 & 13 & 28 & 28 & 8 & 26 & 8 & 41 & 57 & 70 & 57 \\
\hline Eggs & 21 & 21 & 6 & 19 & 21 & 21 & 21 & 21 & 21 & 21 & 21 \\
\hline Nuts and seeds & 25 & 25 & 25 & 25 & 25 & 25 & 25 & 22 & 22 & 25 & 15 \\
\hline Milk and dairy products & 258 & 256 & 285 & 277 & 299 & 267 & 300 & 270 & 252 & 303 & 293 \\
\hline Cheese & 64 & 44 & 47 & 23 & 1 & 33 & 0 & 39 & 48 & 61 & 53 \\
\hline Spreadable and cooking fats & 36 & 26 & 79 & 96 & 22 & 92 & 22 & 80 & 42 & 54 & 32 \\
\hline Drinks & 487 & 1194 & 554 & 969 & 3524 & 1340 & 3201 & 1220 & 1594 & 1191 & 1369 \\
\hline
\end{tabular}

M, male; F, female.

*For five age and gender groups (boys and girls aged 1-3 years; boys and girls aged 4-8 years; girls aged 14-18 years), the optimisation model did not deliver solutions that met the Dietary Reference Values for essential nutrients within the goals set for energy.

the recommendations for the general population. Specific recommendations were defined for these target groups as required.

\section{Deriving criteria and recommendations for foods outside the Wheel of Five}

As the recommended daily amounts of Wheel of Five food groups cover about $85 \%$ of energy requirements, a limited consumption of foods that are not included in the Wheel of Five is possible. This group includes foods that contain relatively high amounts of salt, sugar, TFA or SFA, or are low in fibre. As foods differ in terms of use (like serving size or eating moment) and composition, we decided to develop generic serving-based recommendations, allowing consumers to supplement their diets according to their own preference. A criteria-based distinction was made between foods low in energy and/or unfavourable nutrients, of which at least three servings could be chosen daily, and foods high in energy and/or unfavourable nutrients that should be chosen by exception. Based upon the difference between the recommended maximum intake of energy and the unfavourable nutrients and their provision within the Wheel of Five food groups, it was determined for which nutrients criteria should be set and what the level should be. More details are available elsewhere ${ }^{(45)}$.

\section{Graphical representation and general recommendations}

The Wheel of Five, the Dutch national counselling model since $1953^{(46)}$, was retained for several reasons. First, about $75 \%$ of dietitians in the Netherlands were using the Wheel of Five in 2011 (Netherlands Nutrition Centre, unpublished results). Second, consumer research indicated that in 2015 the Wheel of Five was known by $92 \%$ of the Dutch people, whereas $61 \%$ knew its recommendations (Netherlands Nutrition Centre, unpublished results). The Wheel of Five was adapted to the newly derived recommended daily amounts of food groups and its design updated. Three different concepts, as well as several variants of the finally chosen concept, were tested by consumers and dietitians and discussed with experts on nutrition behaviour and communication. Additionally, general dietary recommendations were formulated and visualised.

\section{Results}

\section{Results of optimisation calculations}

Table 4 shows the results of the optimisation calculations in grams for various food groups. For children aged $1-8$ years and girls aged 14-18 years, the optimisation calculations did not provide a result. For these groups, it was not possible to meet the constraints for essential nutrients within the constraints for energy. For the other age and gender groups, the model provided dietary patterns that met all constraints. There were different solutions for the different age and gender groups. For some food groups, there was no or little variation in optimised amounts across age and gender groups, e.g. for fruit (all $200 \mathrm{~g}$ ) and fish and shellfish (range 15-18g). Other food groups showed a large variation in optimised amounts, e.g. for vegetables (range 200-700 g) and drinks (range 487-3524 g).

\section{Recommended daily amounts for food groups}

The results of the optimised dietary patterns served as a basis for deriving the recommended daily amounts for food groups (Tables 5 and 6). To send consistent and understandable messages to consumers, the results of the optimisation calculations were converted from grams to practical 


\section{Public Health Nutrition}

Table 5 Recommended daily amounts of food groups for children in the food-based dietary guidelines for the Netherlands*

\begin{tabular}{|c|c|c|c|c|c|c|c|}
\hline \multirow[b]{2}{*}{ Food group } & \multirow{2}{*}{$\frac{1-3 \text { years }}{M+F}$} & \multirow{2}{*}{$\frac{4-8 \text { years }}{M+F}$} & \multicolumn{2}{|c|}{$9-13$ years } & \multicolumn{2}{|c|}{$14-18$ years } & \multirow[b]{2}{*}{ Serving unit and serving size } \\
\hline & & & M & $\mathrm{F}$ & M & $\mathrm{F}$ & \\
\hline \multicolumn{8}{|l|}{ Daily recommended } \\
\hline Vegetables & $50-100 \mathrm{~g}$ & $100-150 \mathrm{~g}$ & $150-200 \mathrm{~g}$ & $150-200 \mathrm{~g}$ & $250 \mathrm{~g}$ & $250 \mathrm{~g}$ & $50 \mathrm{~g}$ \\
\hline Fruit & $150 \mathrm{~g}$ & $150 \mathrm{~g}$ & $200 \mathrm{~g}$ & $200 \mathrm{~g}$ & $200 \mathrm{~g}$ & $200 \mathrm{~g}$ & $100 \mathrm{~g}$ \\
\hline Bread & $2-3$ slices & 2-4 slices & 5-6 slices & $4-5$ slices & 6-8 slices & $4-5$ slices & Slice: $35 \mathrm{~g}$ \\
\hline Cereal products and potatoes $\dagger$ & $1-2$ servings & $2-3$ servings & $4-5$ servings & $3-5$ servings & 6 servings & $4-5$ servings & $\begin{array}{l}\text { Tablespoon of cereals: } 50 \mathrm{~g} \\
\text { Medium potato: } 70 \mathrm{~g}\end{array}$ \\
\hline Nuts and seeds & $15 \mathrm{~g}$ & $15 \mathrm{~g}$ & $25 \mathrm{~g}$ & $25 \mathrm{~g}$ & $25 \mathrm{~g}$ & $25 \mathrm{~g}$ & Handful: $15-25 \mathrm{~g}$ \\
\hline Dairy products & 2 servings & 2 servings & 3 servings & 3 servings & 4 servings & 3 servings & Glass or small bowl: $150 \mathrm{~g}$ \\
\hline Cheese & - & $20 \mathrm{~g}$ & $20 \mathrm{~g}$ & $20 \mathrm{~g}$ & $40 \mathrm{~g}$ & $40 \mathrm{~g}$ & For slice of bread: $20 \mathrm{~g}$ \\
\hline Spreadable and cooking fats & $30 \mathrm{~g}$ & $30 \mathrm{~g}$ & $45 \mathrm{~g}$ & $40 \mathrm{~g}$ & $55 \mathrm{~g}$ & $40 \mathrm{~g}$ & $\begin{array}{l}\text { Serving of spreadable fat: } 6 \mathrm{~g} \\
\text { Serving of cooking fat: } 15 \mathrm{~g}\end{array}$ \\
\hline Drinks & $650 \mathrm{ml}$ & $850 \mathrm{ml}$ & $1000 \mathrm{ml}$ & $900 \mathrm{ml}$ & $1300 \mathrm{ml}$ & $1000 \mathrm{ml}$ & $\begin{array}{l}\text { Glass: } 150 \mathrm{ml} \\
\text { Beaker: } 250 \mathrm{ml}\end{array}$ \\
\hline \multicolumn{8}{|l|}{ Weekly recommended } \\
\hline Fish and shellfish & 0.5 serving & 0.5 serving & 1 serving & 1 serving & 1 serving & 1 serving & $100 \mathrm{~g}$ unprepared fish \\
\hline Legumes & 0.5 serving & $1-2$ servings & 2 servings & 2 servings & $2-3$ servings & $2-3$ servings & Tablespoon: $60 \mathrm{~g}$ \\
\hline $\begin{array}{l}\text { Meat (maximum) } \\
\text { of which max red meat }\end{array}$ & $\max 250 \mathrm{~g}$ & $\max 250 \mathrm{~g}$ & $\begin{array}{l}500 \mathrm{~g} \\
300 \mathrm{~g}\end{array}$ & $\begin{array}{l}500 \mathrm{~g} \\
300 \mathrm{~g}\end{array}$ & $\begin{array}{l}500 \mathrm{~g} \\
300 \mathrm{~g}\end{array}$ & $\begin{array}{l}500 \mathrm{~g} \\
300 \mathrm{~g}\end{array}$ & $100 \mathrm{~g}$ unprepared meat \\
\hline Eggs & $1-2$ eggs & $2-3$ eggs & $2-3$ eggs & $2-3$ eggs & $2-3$ eggs & $2-3$ eggs & Egg: $50 \mathrm{~g}$ \\
\hline
\end{tabular}

M, male; F, female.

*Recommended daily amounts of food groups provide about $85 \%$ of the energy requirement.

†Half of this amount should consist of whole-wheat products each week. 


\section{Public Health Nutrition}

Table 6 Recommended daily amounts of food groups for adults in the food-based dietary guidelines for the Netherlands*

\begin{tabular}{|c|c|c|c|c|c|c|c|c|c|}
\hline \multirow[b]{2}{*}{ Food group } & \multicolumn{2}{|c|}{$19-50$ years } & \multicolumn{2}{|c|}{$51-69$ years } & \multicolumn{2}{|c|}{$\geq 70$ years } & \multirow[b]{2}{*}{ Pregnant } & \multirow[b]{2}{*}{ Lactating } & \multirow[b]{2}{*}{ Serving unit and serving size } \\
\hline & M & $\mathrm{F}$ & M & $\mathrm{F}$ & M & $\mathrm{F}$ & & & \\
\hline \multicolumn{10}{|l|}{ Daily recommended } \\
\hline Vegetables & $250 \mathrm{~g}$ & $250 \mathrm{~g}$ & $250 \mathrm{~g}$ & $250 \mathrm{~g}$ & $250 \mathrm{~g}$ & $250 \mathrm{~g}$ & $250 \mathrm{~g}$ & $250 \mathrm{~g}$ & $50 \mathrm{~g}$ \\
\hline Fruits & $200 \mathrm{~g}$ & $200 \mathrm{~g}$ & $200 \mathrm{~g}$ & $200 \mathrm{~g}$ & $200 \mathrm{~g}$ & $200 \mathrm{~g}$ & $200 \mathrm{~g}$ & $200 \mathrm{~g}$ & $100 \mathrm{~g}$ \\
\hline Bread & $6-8$ slices & $4-5$ slices & 6-7 slices & 3-4 slices & 4-6 slices & 3-4 slices & 4-7 slices & $6-7$ slices & Slice: $35 \mathrm{~g}$ \\
\hline Cereal products and potatoes $\dagger$ & $4-5$ servings & $4-5$ servings & 4 servings & 3-4 servings & 4 servings & 3 servings & $4-5$ servings & $4-5$ servings & $\begin{array}{l}\text { Tablespoon of cereals: } 50 \mathrm{~g} \\
\text { Medium potato: } 70 \mathrm{~g}\end{array}$ \\
\hline Nuts and seeds & $25 \mathrm{~g}$ & $25 \mathrm{~g}$ & $25 \mathrm{~g}$ & $15 \mathrm{~g}$ & $15 \mathrm{~g}$ & $15 \mathrm{~g}$ & $25 \mathrm{~g}$ & $50 \mathrm{~g}$ & Handful: $15-25 \mathrm{~g}$ \\
\hline Milk and dairy products & 2-3 servings & $2-3$ servings & 3 servings & 3-4 servings & 4 servings & 4 servings & $2-3$ servings & $2-3$ servings & Glass or small bowl: $150 \mathrm{~g}$ \\
\hline Cheese & $40 \mathrm{~g}$ & $40 \mathrm{~g}$ & $40 \mathrm{~g}$ & $40 \mathrm{~g}$ & $40 \mathrm{~g}$ & $40 \mathrm{~g}$ & $40 \mathrm{~g}$ & $40 \mathrm{~g}$ & For slice of bread: $20 \mathrm{~g}$ \\
\hline Spreadable and cooking fats & $65 \mathrm{~g}$ & $40 \mathrm{~g}$ & $65 \mathrm{~g}$ & $40 \mathrm{~g}$ & $55 \mathrm{~g}$ & $35 \mathrm{~g}$ & $40-50 \mathrm{~g}$ & $50 \mathrm{~g}$ & $\begin{array}{l}\text { Serving of spreadable fat: } 6 \mathrm{~g} \\
\text { Serving of cooking fat: } 15 \mathrm{~g}\end{array}$ \\
\hline Drinks & $1500 \mathrm{ml}$ & $1100 \mathrm{ml}$ & $1400 \mathrm{ml}$ & $950 \mathrm{ml}$ & $1300 \mathrm{ml}$ & $900 \mathrm{ml}$ & $1500 \mathrm{ml}$ & $1500 \mathrm{ml}$ & $\begin{array}{l}\text { Glass: } 150 \mathrm{ml} \\
\text { Beaker: } 250 \mathrm{ml}\end{array}$ \\
\hline \multicolumn{10}{|l|}{ Weekly recommended } \\
\hline Fish and shellfish & 1 serving & 1 serving & 1 serving & 1 serving & 1 serving & 1 serving & 1 serving & 1 serving & $100 \mathrm{~g}$ unprepared fish \\
\hline Legumes & $2-3$ servings & $2-3$ servings & $2-3$ servings & $2-3$ servings & $2-3$ servings & $2-3$ servings & $2-3$ servings & $2-3$ servings & Tablespoon: $60 \mathrm{~g}$ \\
\hline $\begin{array}{l}\text { Meat (maximum) } \\
\text { of which max red meat }\end{array}$ & $\begin{array}{l}500 \mathrm{~g} \\
300 \mathrm{~g}\end{array}$ & $\begin{array}{l}500 \mathrm{~g} \\
300 \mathrm{~g}\end{array}$ & $\begin{array}{l}500 \mathrm{~g} \\
300 \mathrm{~g}\end{array}$ & $\begin{array}{l}500 \mathrm{~g} \\
300 \mathrm{~g}\end{array}$ & $\begin{array}{l}500 \mathrm{~g} \\
300 \mathrm{~g}\end{array}$ & $\begin{array}{l}500 \mathrm{~g} \\
300 \mathrm{~g}\end{array}$ & $\begin{array}{l}500-675 \mathrm{~g} \\
300-385 \mathrm{~g}\end{array}$ & $\begin{array}{l}675 \mathrm{~g} \\
385 \mathrm{~g}\end{array}$ & $100 \mathrm{~g}$ unprepared meat \\
\hline Eggs & $2-3$ eggs & $2-3$ eggs & $2-3$ eggs & $2-3$ eggs & $2-3$ eggs & $2-3$ eggs & $2-3$ eggs & $2-3$ eggs & Egg: $50 \mathrm{~g}$ \\
\hline
\end{tabular}

M, male; $F$, female.

* $\mathrm{R}$.

tHalf of this amount should consist of whole-wheat products each week. 
Table 7 Daily amounts of nutrients delivered by the daily recommended amounts for foods in the Wheel of Five per age and gender ${ }^{\star}, \dagger$

\begin{tabular}{|c|c|c|c|c|c|c|c|c|c|c|c|c|c|c|c|c|c|c|}
\hline \multirow[b]{2}{*}{ Nutrient (unit per day) } & \multicolumn{2}{|c|}{$1-3$ years } & \multicolumn{2}{|c|}{$4-8$ years } & \multicolumn{2}{|c|}{$9-13$ years } & \multicolumn{2}{|c|}{$14-18$ years } & \multicolumn{2}{|c|}{$19-30$ years } & \multicolumn{2}{|c|}{$31-50$ years } & \multicolumn{2}{|c|}{$51-69$ years } & \multicolumn{2}{|c|}{$\geq 70$ years } & \multirow[b]{2}{*}{ Pregnant } & \multirow[b]{2}{*}{ Lactating } \\
\hline & M & $\mathrm{F}$ & M & $\mathrm{F}$ & M & $\mathrm{F}$ & M & $\mathrm{F}$ & $M$ & $\mathrm{~F}$ & M & $\mathrm{F}$ & M & $\mathrm{F}$ & M & $\mathrm{F}$ & & \\
\hline Energy (kJ) & 3787 & 3787 & 4682 & 4682 & 7544 & 6916 & 9364 & 7393 & 8740 & 7303 & 8740 & 7303 & 8527 & 6602 & 7745 & 6456 & 7824 & 9000 \\
\hline Energy (kcal) & 905 & 905 & 1119 & 1119 & 1803 & 1653 & 2238 & 1767 & 2089 & 1745 & 2089 & 1745 & 2038 & 1578 & 1851 & 1543 & 1870 & 2151 \\
\hline Protein (g) & 39 & 39 & 50 & 50 & 81 & 76 & 102 & 84 & 94 & 84 & 94 & 84 & 93 & 81 & 93 & 84 & 90 & 100 \\
\hline Total fatty acids (g) & 34 & 34 & 41 & 41 & 65 & 61 & 78 & 65 & 81 & 64 & 81 & 64 & 81 & 58 & 67 & 55 & 68 & 86 \\
\hline SFA (g) & 9 & 9 & 12 & 12 & 17 & 16 & 22 & 18 & 20 & 17 & 20 & 17 & 20 & 17 & 19 & 17 & 18 & 21 \\
\hline PUFA (g) & 11 & 11 & 13 & 13 & 21 & 20 & 25 & 20 & 26 & 19 & 26 & 19 & 26 & 17 & 21 & 16 & 21 & 27 \\
\hline Linoleic acid $(\mathrm{g})$ & 9 & 9 & 11 & 11 & 18 & 17 & 21 & 17 & 22 & 16 & 22 & 16 & 22 & 14 & 17 & 13 & 18 & 23 \\
\hline Trans-fatty acids (g) & 0.3 & 0.3 & 0.3 & 0.3 & 0.5 & 0.4 & 0.6 & 0.5 & 0.6 & 0.5 & 0.6 & 0.5 & 0.6 & 0.5 & 0.6 & 0.5 & 0.5 & 0.5 \\
\hline$\alpha$-Linolenic acid (g) & $1 \cdot 1$ & $1 \cdot 1$ & 1.5 & 1.5 & $2 \cdot 6$ & $2 \cdot 4$ & $3 \cdot 1$ & $2 \cdot 4$ & $3 \cdot 3$ & $2 \cdot 4$ & $3 \cdot 3$ & 2.4 & 3.2 & $2 \cdot 2$ & 3.3 & 2.5 & $2 \cdot 6$ & $3 \cdot 2$ \\
\hline $\mathrm{EPA}+\mathrm{DHA}(\mathrm{mg})$ & 193 & 193 & 222 & 222 & 397 & 395 & 406 & 397 & 399 & 389 & 399 & 389 & 399 & 386 & 405 & 395 & 393 & 406 \\
\hline Cholesterol (mg) & 83 & 83 & 122 & 122 & 158 & 157 & 178 & 168 & 163 & 162 & 163 & 162 & 166 & 168 & 173 & 171 & 167 & 172 \\
\hline Total carbohydrate $(\mathrm{g})$ & 104 & 104 & 127 & 127 & 208 & 186 & 262 & 197 & 229 & 193 & 229 & 193 & 217 & 168 & 201 & 163 & 207 & 226 \\
\hline Mono- and disaccharides (g) & 37 & 37 & 39 & 39 & 56 & 55 & 66 & 57 & 54 & 52 & 54 & 52 & 57 & 57 & 61 & 59 & - & - \\
\hline Dietary fibre $(\mathrm{g})$ & 13 & 13 & 18 & 18 & 29 & 26 & 36 & 28 & 35 & 30 & 35 & 30 & 33 & 25 & 31 & 25 & 32 & 35 \\
\hline Water (g) & 1244 & 1244 & 1573 & 1573 & 2202 & 1967 & 2701 & 2168 & 2636 & 2194 & 2636 & 2194 & 2578 & 2127 & 2586 & 2121 & 2615 & 2638 \\
\hline Vitamin A $(\mu \mathrm{g})$ & 416 & 416 & 491 & 491 & 661 & 633 & 865 & 758 & 849 & 707 & 849 & 707 & 857 & 724 & 913 & 783 & 738 & 769 \\
\hline Vitamin D ( $\mu \mathrm{g})$ & 3 & 3 & 3 & 3 & 4 & 4 & 5 & 4 & 5 & 4 & 5 & 4 & 5 & 4 & 5 & 4 & 4 & 5 \\
\hline Vitamin E (mg) & 8 & 8 & 10 & 10 & 15 & 14 & 18 & 14 & 19 & 14 & 19 & 14 & 18 & 13 & 15 & 12 & 15 & 18 \\
\hline Vitamin $\mathrm{K}(\mu \mathrm{g})$ & 109 & 109 & 140 & 140 & 186 & 181 & 255 & 239 & 273 & 250 & 273 & 250 & 273 & 251 & 226 & 218 & 255 & 260 \\
\hline Thiamin (mg) & 0.7 & 0.7 & 0.8 & 0.8 & $1 \cdot 2$ & 1.2 & 1.5 & $1 \cdot 2$ & 1.4 & 1.2 & 1.4 & 1.2 & 1.3 & 1.1 & 1.2 & 1.0 & 1.3 & 1.5 \\
\hline Riboflavin (mg) & 1.0 & $1 \cdot 0$ & $1 \cdot 1$ & $1 \cdot 1$ & $1 \cdot 6$ & $1 \cdot 6$ & $2 \cdot 1$ & 1.7 & $1 \cdot 7$ & 1.5 & $1 \cdot 7$ & 1.5 & $1 \cdot 8$ & $1 \cdot 7$ & 1.9 & 1.8 & 1.6 & 1.7 \\
\hline Niacin (mg) & 9 & 9 & 10 & 10 & 17 & 16 & 21 & 17 & 21 & 19 & 21 & 19 & 20 & 17 & 19 & 16 & 20 & 23 \\
\hline Vitamin $\mathrm{B}_{6}(\mathrm{mg})$ & 1.0 & 1.0 & 1.2 & $1 \cdot 2$ & 1.9 & 1.8 & 2.3 & 1.9 & $2 \cdot 1$ & 1.8 & $2 \cdot 1$ & 1.8 & $2 \cdot 0$ & 1.7 & $2 \cdot 0$ & 1.7 & 2.0 & $2 \cdot 1$ \\
\hline Folate $(\mu \mathrm{g})$ & 135 & 135 & 189 & 189 & 293 & 273 & 375 & 311 & 376 & 328 & 376 & 328 & 370 & 310 & 388 & 337 & 347 & 377 \\
\hline Vitamin $\mathrm{B}_{12}(\mathrm{mg})$ & $2 \cdot 3$ & $2 \cdot 3$ & $2 \cdot 7$ & $2 \cdot 7$ & $4 \cdot 1$ & 4.0 & $5 \cdot 1$ & 4.3 & 4.0 & 3.9 & 4.0 & 3.9 & 4.3 & 4.4 & 4.8 & 4.7 & 4.0 & $4 \cdot 1$ \\
\hline Vitamin C (mg) & 38 & 38 & 50 & 50 & 74 & 73 & 91 & 85 & 97 & 97 & 97 & 97 & 96 & 95 & 103 & 100 & 97 & 98 \\
\hline Calcium (mg) & 592 & 592 & 792 & 792 & 1101 & 1063 & 1532 & 1258 & 1253 & 1178 & 1253 & 1178 & 1331 & 1325 & 1470 & 1415 & 1216 & 1257 \\
\hline Phosphorus (mg) & 806 & 806 & 1030 & 1030 & 1600 & 1515 & 2053 & 1677 & 1839 & 1682 & 1839 & 1682 & 1856 & 1664 & 1922 & 1756 & 1764 & 1974 \\
\hline Magnesium (mg) & 203 & 203 & 249 & 249 & 402 & 371 & 498 & 400 & 488 & 428 & 488 & 428 & 473 & 376 & 446 & 380 & 460 & 543 \\
\hline Sodium (mg) & 721 & 721 & 962 & 962 & 1540 & 1356 & 2015 & 1494 & 1914 & 1493 & 1914 & 1493 & 1846 & 1350 & 1645 & 1362 & 1671 & 1849 \\
\hline Potassium (mg) & 1715 & 1715 & 2082 & 2082 & 3257 & 3099 & 4056 & 3392 & 3860 & 3568 & 3860 & 3568 & 3835 & 3465 & 3912 & 3512 & 3781 & 4049 \\
\hline Iron (mg) & 5 & 5 & 6 & 6 & 10 & 9 & 13 & 10 & 13 & 11 & 13 & 11 & 12 & 9 & 11 & 9 & 12 & 14 \\
\hline Zinc (mg) & 5 & 5 & 7 & 7 & 11 & 10 & 14 & 12 & 13 & 12 & 13 & 12 & 13 & 11 & 13 & 12 & 12 & 14 \\
\hline Selenium $(\mu \mathrm{g})$ & 26 & 26 & 33 & 33 & 53 & 50 & 64 & 55 & 61 & 56 & 61 & 56 & 59 & 50 & 53 & 48 & 59 & 70 \\
\hline Copper (mg) & 0.7 & 0.7 & 0.9 & 0.9 & 1.4 & 1.3 & 1.7 & 1.4 & 1.7 & 1.5 & 1.7 & 1.5 & 1.7 & 1.3 & 1.4 & $1 \cdot 2$ & 1.6 & 2.0 \\
\hline lodine $(\mu \mathrm{g})$ & 102 & 102 & 123 & 123 & 205 & 180 & 258 & 185 & 243 & 182 & 243 & 182 & 236 & 167 & 213 & 174 & 208 & 233 \\
\hline
\end{tabular}

*Daily recommended amounts of foods deliver about $85 \%$ of the energy requirements.

†Figures in bold do not reach the Dietary Reference Values of the Health Council of the Netherlands ${ }^{(21)}$. 
quantities or serving sizes. The outcome of the optimisation calculations, the HCNL advice on food groups and nutrients, closest adherence to current consumption, environmental impact and serving size were all taken into account. For example, for vegetables the amount in the optimised diets varied between 200 and $700 \mathrm{~g}$ for different target groups. The HCNL recommendation of at least $200 \mathrm{~g}$ of vegetables daily resulted in a somewhat lower vitamin A and folic acid provision in specific subgroups (results not shown). For most population groups, the optimisation calculations resulted in amounts between 235 and $271 \mathrm{~g}$ (Table 4). As we use $50 \mathrm{~g}$ of vegetables as the visualisation of a serving for consumers, we decided to recommend $250 \mathrm{~g}$ vegetables/d.

Table 7 shows the provision of nutrients by the recommended daily amounts of foods. These amounts provided about $85 \%$ of the energy needed and, except for a few cases, at least $100 \%$ of the nutrient DRV. The implication of each exception was evaluated, taking account of the difference with the DRV and the current intake of the specific nutrient. More detailed information is available ${ }^{(38)}$. If applicable, specific points of attention were defined for recommendations to consumers in case of an intake below the DRV, e.g. the use of sufficient leafy green vegetables to provide (pro)vitamin A, the consumption of wholegrain cereals to provide dietary fibre and the consumption of sufficient milk products to provide calcium. For young children and women of childbearing age having an iron intake below the DRV (Table 7), the advice is to consume foods that are naturally rich in iron and to use combinations of foods to enhance iron absorption (fruits and cereal products) ${ }^{(47)}$. Given those specific recommendations, experts expressed no concerns about nutrient adequacy for people who consume the recommended daily amounts of foods.

\section{Recommendations for target groups with higher energy requirements and different food preferences}

Higher energy needs. Recommendations for pregnant and breast-feeding women were based on the recommendations for women aged 19-50 years (Table 6), fitting into the habitual dietary pattern ${ }^{(22)}$. To meet the higher nutrient and energy requirements for pregnant and breast-feeding women $^{(21,31)}$ the recommendation is to consume up to two extra slices of bread with margarine and $25 \mathrm{~g}$ extra meat/d, depending on energy needs and activity level. For breast-feeding women, an extra $25 \mathrm{~g}$ nuts/d is recommended to meet their higher nutrient and energy requirements ${ }^{(21,31)}$. Additionally, the advice for pregnant women is to use folic acid supplements in the most vulnerable period of pregnancy ${ }^{(48)}$ and vitamin $\mathrm{D}$, in line with $\mathrm{HCNL}^{(41)}$.

The physical activity level value used for active groups resulted in a 9-15\% higher energy requirement. For these groups, we drafted the advice to consume more plantbased foods like bread, wholegrain cereals, legumes and nuts to meet this extra energy requirement.
No meat. For those with a dietary pattern without meat, but including fish, a dietary pattern similar to that in Tables 5 and 6 is recommended in which the meat is replaced by a combination of nuts $(2 \times 25 \mathrm{~g} /$ week extra $)$, legumes ( $135 \mathrm{~g} /$ week extra) and eggs (1 egg/week extra). Nutrient provision of these recommendations was evaluated (data not shown; see elsewhere ${ }^{(38)}$ for more details), which resulted in specific recommendations to consume foods naturally rich in iron, to use sufficient dairy and wholegrain products and to consume meat replacements with sufficient protein and enriched with iron and thiamin or vitamin $\mathrm{B}_{12}$.

Non-Western dietary patterns. When applying the recommended daily amounts for food groups as shown in Table 6 for people with Turkish, Moroccan and Surinamese backgrounds using their own typical products, the DRV for $\alpha$-linoleic acid, vitamin A and vitamin D were not met (results available elsewhere ${ }^{(38)}$ ). In order to provide sufficient nutrients, specific recommendations for foods were drafted for these subgroups, like to use of leafy green vegetables and margarines for (pro)vitamin A and to choose fats and oils rich in $\alpha$-linoleic acid. Additionally, for these subgroups HCNL advises the daily use of vitamin D supplements $^{(41)}$.

\section{Criteria and recommendations for foods outside the Wheel of Five}

Our calculations showed that energy, SFA and salt were limiting factors for foods outside the Wheel of Five. That is, for these factors, the intake through the recommended daily amounts of food groups was already relatively close to the maximum intake levels; for instance, about $20 \%$ for SFA (women aged 31-50 years) and 20\% for salt (men aged $31-50$ years) ${ }^{(38)}$. Criteria for these factors to discriminate between foods that could be consumed at least three times daily and foods that should be consumed exceptionally were: $314 \mathrm{~kJ}$ ( $75 \mathrm{kcal}), 1.7 \mathrm{~g}$ SFA and $0.5 \mathrm{~g}$ salt per serving. With these criteria, maximum recommendations for energy, SFA and salt were not exceeded by three daily choices, and left some room for weekly choices (data not shown; see elsewhere ${ }^{(45)}$ for more details). Sugarcontaining beverages like soft drinks and juices have their own, very distinctive criterion $(16.7 \mathrm{~kJ}$ ( $4 \mathrm{kcal})$ per $100 \mathrm{ml})$ to distinguish between daily and weekly choices. Recommendations for foods outside the Wheel of Five are: 'Consume daily choices no more than three to five times per day, and weekly choices no more than three times a week'

\section{Grapbical representation and general recommendations}

The Dutch national dietary-counselling model is the Wheel of Five (Fig. 2). It includes five sections representing the combinations of food groups given in Tables 5 and 6. The graphical size of each section was determined as the ratio of the recommended amounts (in grams) for 


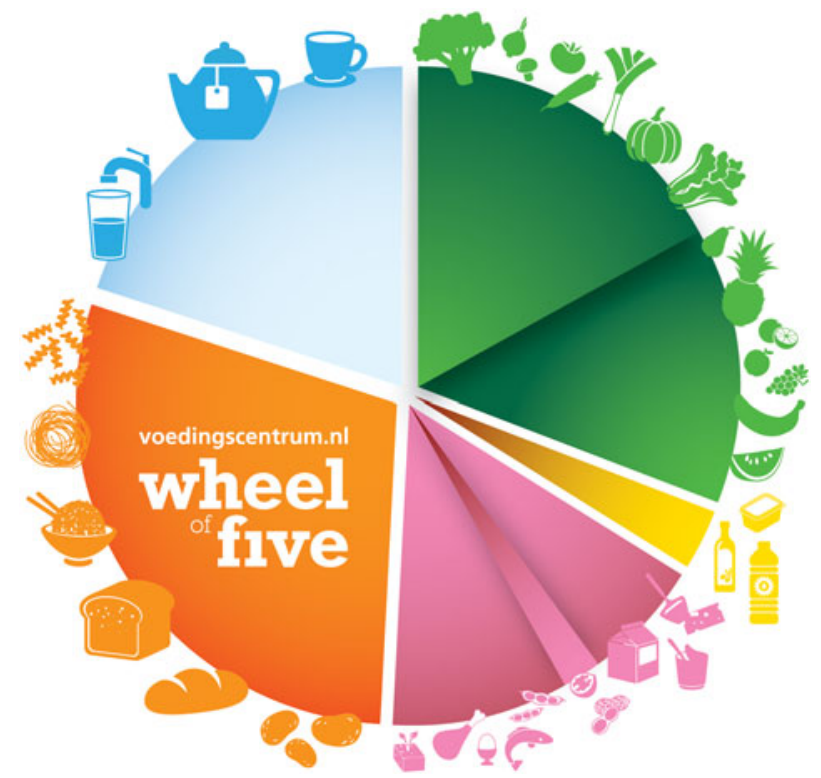

Fig. 2 Wheel of Five: graphical representation of the foodbased dietary guidelines for the Netherlands
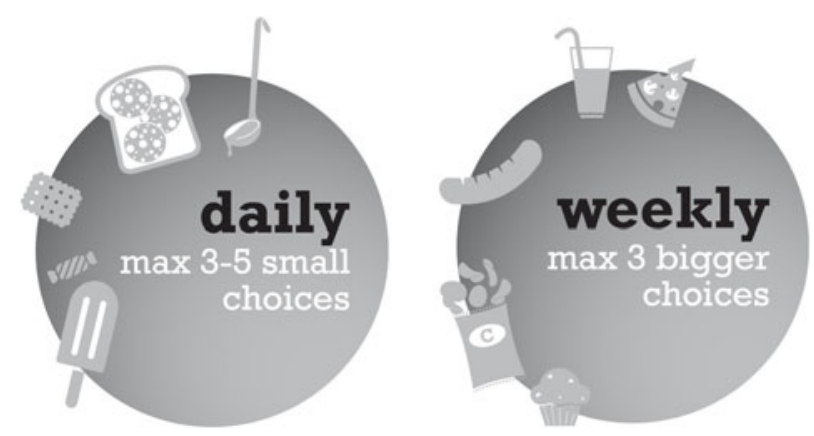

Fig. 3 Graphical representation of recommendations for products outside the Wheel of Five for daily choices (left) and weekly choices (right)

adult women, except for drinks (this was pre-set as onefifth of the Wheel). The icons represent the food groups in each section. To represent each food group, the more environmentally friendly options were chosen. For fruit and vegetables, for instance, icons were chosen for foods that are available year-round and have a low environmental impact according to the Fruit and Vegetable Calendar ${ }^{(49)}$.

The recommended dietary patterns for the different age and gender groups (Tables 5 and 6) were summarised in seven general recommendations for the Wheel of Five:

- $\quad$ Eat lots of fruit and vegetables.

- Consume mainly wholegrain products such as wholegrain bread, wholegrain pasta and brown rice.

- $\quad$ Eat less meat and more plant-based foods, and vary with fish, pulses, nuts, eggs and vegetarian products.

- Consume sufficient dairy products such as milk, yoghurt and cheese.
- $\quad$ Eat a handful of unsalted nuts daily.

- Consume soft and liquid spreadable fats and cooking fats.

- Drink sufficient amounts of tap water, tea and coffee.

Figure 3 shows the graphical representation for foods outside the Wheel of Five. In all cases, the general advice is that these foods should neither be eaten too often nor in large quantities. It is recommended to use small servings, defined by the energy, SFA and salt content per serving, to prevent undesirable weight gain.

\section{Discussion}

The present paper describes the process, choices made and results of the development of the FBDG for the Netherlands. A consumption pattern in line with these guidelines reduces the risk of major chronic diseases, supplies adequate amounts of energy and nutrients, and can reduce the environmental impact compared with the mean current consumption. The process described in the present paper combined model and data-based elements with expert knowledge and common sense. The FBDG for the Netherlands consist of a graphical representation in the Wheel of Five, a set of seven general dietary guidelines, and quantitative recommended dietary patterns for several target groups. In terms of the general guidelines, there is a large similarity with the FBDG for other countries. Most FBDG promote an abundant consumption of fruit, vegetables and wholegrain cereals, and a limited consumption of products rich in SFA, TFA, simple sugars and salt ${ }^{(3,50)}$. A plate or circle as a graphical representation is also used in many other countries, as is the pyramid shape. The type of shape for practical nutrition communication does not play a major role in the effectiveness or efficiency of this communication $^{(51)}$.

A consistent set of quantitative guidelines for a broad range of target groups is typical for the FBDG for the Netherlands. Apart from the usual subgroups by age and gender, and pregnant and breast-feeding women, these cover persons with culturally different diets because of immigrant backgrounds or specific dietary regimens (pescatarians). Few other FBDG are so broadly developed. In Europe, Italy and Albania include advice for menopausal women, and the UK for Asians ${ }^{(3)}$. In the Americas, some countries include specific dietary guidelines for vegetarians (Canada, Brazil, Puerto Rico and the USA), indigenous people (Canada and Venezuela), inhabitants of rural areas (Colombia and Peru), victims of violence (Colombia) and pregnant teenagers (Peru and Cuba) ${ }^{(50)}$. Target-groupspecific guidelines are important because of differences in dietary requirements and in order to make the messages more culturally acceptable. The latter was also the reason why the current diet was chosen as an optimisation criterion in the optimisation modelling step of the Wheel of Five process. 
A shift from the current Dutch food consumption pattern to a food pattern according to the Wheel of Five will result in a higher consumption of vegetables, fruits, wholegrain foods, nuts, fish and legumes, whereas the consumption of foods with a negative impact on health would be lower ${ }^{(52)}$. These changes in dietary pattern are associated with a reduction of the risk of chronic diseases and thus will result in health gain ${ }^{(20)}$. Kromhout et $a l^{(20)}$ argue that the maximum health gain cannot be quantified. They showed that relative risks per food group are of the order of 10-20\%, but indicate that because of the correlations among food groups, the effects are not additive. However, the results of the PREDIMED (Prevención con Dieta Mediterránea; Prevention with a Mediterranean Diet) study suggest that the more the guidelines are adhered to, the greater the health gain compared with findings of cohort studies on dietary patterns ${ }^{(53)}$.

Despite the substantial evidence base showing the need and possibilities for aligning health and environmental objectives, only a few countries have so far included environmental sustainability in their FBDG. An inventory of the FAO published in 2016 identified Germany, Brazil, Sweden and Qatar ${ }^{(7)}$. More recently, the guidelines of Belgium for the Flemish population and for the UK also included environmental sustainability ${ }^{(8,54)}$. There are a number of factors that affect the sustainability of our food system, for example GHGE, land use and water use, but also pesticide use, animal welfare and food waste ${ }^{(55-59)}$. Van Dooren et al. evaluated fifty-five documented assessment methods of indicators for environmental impact and showed that the majority of the indicators cannot be used to assess the environmental impacts of diets because there is a lack of reliable data or internationally adapted methods and support. They concluded that GHGE and land use cover most of the environmental impact of diets ${ }^{(58)}$. GHGE is far and away the most commonly used indicator ${ }^{(60)}$. GHGE is also strongly correlated with land use, water use, acidification, freshwater eutrophication and marine eutrophication ${ }^{(61)}$. Per kilogram of product, meat and cheese have considerably higher GHGE compared with plant-based foods, i.e. $12-13 v .<3 \mathrm{~kg} \mathrm{CO}_{2}$-equivalents ${ }^{(62)}$. For this reason, we set a maximum level for animal food groups in our optimisation model as a proxy for GHGE. This is also in line with the HCNL recommendation to follow a diet with less animal-based foods ${ }^{(20,26)}$. For most age groups, our optimisation results were at the pre-set maximum for total meat and eggs. This shows that without applying these constraints, the outcome of the optimisation model most likely would have resulted in a higher recommended intake of these animal-based foods, thus in diets with higher GHGE, since these foods are rich sources of several essential nutrients.

We did not intend to create FBDG for diets with the least environmental impact possible. This would require optimisation modelling with minimising an indicator like GHGE as objective function. Studies that did optimise for minimal GHGE showed that high reductions in GHGE resulted in dietary patterns that were not acceptable and/or not nutritionally adequate ${ }^{(63,64)}$. These studies also showed that sustainable dietary patterns that meet dietary requirements for health could be reached without eliminating meat or dairy products. A food pattern according to the Wheel of Five recommends a maximum consumption of $500 \mathrm{~g}$ of meat weekly. Particularly for adult men, this means a significant reduction compared with their current observed average meat consumption of $930 \mathrm{~g} / \mathrm{week}^{(22)}$. For adult women, who currently consume $615 \mathrm{~g} /$ week $^{(22)}$, this reduction is less substantial. Recently, Van de Kamp et al. ${ }^{(61)}$ showed that the shift from the current Dutch diet to the recommended dietary pattern in the Wheel of Five reduces GHGE up to $13 \%$ for men aged 31-50 years, whereas they increase slightly by $2-5 \%$ for women. More substantial reductions in GHGE are achieved with a further reduction of meat and replacing it by nuts, legumes and eggs. Alternatively, substantial reductions can be achieved by consuming only foods and beverages with relatively low GHGE within each food group, such as drinking tap water, coffee and tea and limiting the consumption of highly processed foods ${ }^{(61)}$. In line with this, the Netherlands Nutrition Centre provides additional practical advice for consumers to help them to make more sustainable choices: for instance, by examples of weekly menus that include four daily menus with meat and three daily menus with meat alternatives; by the recommendation to eat local fruits and vegetables of the season ${ }^{(65)}$; as well as by practical recommendations to prevent food waste and providing information on animal welfare and sustainability labels.

The recommended amounts for foods in the Wheel of Five provide approximately $85 \%$ of the average energy requirement. Consequently, consumers who adhere to these dietary patterns can supplement their diet with other foods that are not part of the Wheel of Five, for example with processed foods that do not fulfil the salt, sugar, fibre or fatty acid criteria of the Wheel of Five, and sweet and salty snacks. Obtaining on average $15 \%$ of the energy requirement from foods outside the Wheel of Five is a much lower figure than the observed consumption level in the Netherlands of about two-thirds of energy intake ${ }^{(45)}$. Other FBDG also indicate that the consumption of products rich in salt, sugar and SFA should be limited ${ }^{(8,14)}$. To the best of our knowledge, the Wheel of Five guidelines are unique in the sense that they provide practical recommendations for the consumption frequency and serving sizes of foods with a simple distinction between foods that may be consumed on a daily basis or a weekly basis.

The development process and methods have several strengths and limitations. A transparent and structured procedure was followed that consisted of a combination of data and model-driven steps, complemented by independent expert-based decisions. The optimisation model ensured that the FBDG included adaptations to the current food consumption pattern that were as small as possible, meet the recommendations for food groups and nutrients, 
and limit consumption of animal products with a high environmental impact. Optimisation modelling is considered the preferred approach, since it captures the complexity of the diet as a whole ${ }^{(66)}$, and is applied by several other countries $^{(13-15)}$. The use of an optimisation model requires a range of decisions that potentially can influence the outcome ${ }^{(67)}$. Examples are the definition of food groups and their nutrient composition, the criteria for Wheel of Five food groups, the type of optimisation function (quadratic, linear) and constraints for food groups. As internal validity check, we performed a sensitivity analyses for one of the age and sex groups to study the impact of these choices in the optimisation modelling. Results of nine different scenarios were positively correlated with a reference scenario (Spearman's $r$ ranged from 0.62 to 0.98 with an average of $0 \cdot 87$; data not shown). The lowest correlation was observed in a scenario where all food groups were given a nutrient composition that was healthier, such as higher in essential nutrients and lower in SFA, TFA, sodium or sugar, for example. Among others, this resulted in lower amounts of vegetables and fruits compared with the reference scenario $(136 \mathrm{~g} / \mathrm{d} v .211 \mathrm{~g} / \mathrm{d}$ for vegetables and $88 \mathrm{~g} / \mathrm{d} v .126 \mathrm{~g} / \mathrm{d}$ for fruit). Given the different results with different choices, it is essential that the process and decisions are transparent and documented.

Another limitation was that the optimisation model did not give a solution for some of the target groups. For the Wheel of Five derivation, this was not a problem because we could extrapolate recommendations from adjacent age groups. If no solution had been found for many or all groups, however, an alternative optimisation model approach that searched for a diet that violated the constraints as little as possible would have been preferable ${ }^{(68)}$. A disadvantage of the optimisation model used was that it gave only one optimal solution without providing an insight into other, slightly less optimal solutions. As a consequence, some optimisation results were inconsistent across the target groups, for example daily amounts of wholegrain products for adult men varied from $82 \mathrm{~g} / \mathrm{d}$ for the over 70 s to $200 \mathrm{~g} / \mathrm{d}$ for men aged 19-30 years. A similar observation was made in a Japanese study, which for example recommended daily amounts of 35 and $164 \mathrm{~g}$ of wholegrain products for men aged 30-49 and aged 50-69 years, respectively ${ }^{(13)}$. Overall, developing FBDG remains a combination of science-based and expert-based decisions. Therefore, transparency of the process is warranted.

As indicated before, the FBDG for the Netherlands show a large similarity with the FBDG for other countries. They consistently promote an abundant consumption of fruit, vegetables and whole-grain cereals, and a limited consumption of products rich in SFA, TFA, simple sugars and salt ${ }^{(3,50)}$, showing good external validity. This is also the case when comparing the FBDG for the Netherlands with FBDG for other countries that integrated health and sustainability. Like our recommendations, these
FBDG recommend to consume more plant-based foods, fruits and vegetables, to limit the amount of red and processed meat, and to consume (low-fat, unsweetened) milk and dairy products ${ }^{(7)}$. Sweden and Qatar set maximum recommendations for red and processed meat at $500 \mathrm{~g} /$ week $^{(7)}$. This is higher than our recommendations of $500 \mathrm{~g}$ total meat (of which maximum $300 \mathrm{~g}$ red meat) per week. Recently, Willett et al. ${ }^{(69)}$ presented a dietary pattern that integrated health and sustainability, aiming at feeding the global population in 2050 within the planetary boundaries. This dietary pattern was characterised by mean recommended intakes of food groups and ranges around the mean to meet e.g. regional or cultural differences. Although our recommendations for fish, legumes and nuts are lower than the mean value given in this dietary pattern, whereas our recommendations for total meat, dairy products and potatoes are higher, our food group recommendations are, except for potatoes, within the indicated ranges. As described before, we stimulate consumers towards a more plant-based, less animal-based food pattern.

Dietary guidelines are a key component of a coherent food policy and are the basis for the development of policies intended to shift consumption patterns in healthier and more environmentally sustainable directions. They need to be widely communicated to health professionals and the general public. They also need to be linked to other food policies and interventions ${ }^{(7)}$, such as food reformulation, measures to create healthier food environments, and regulations on food marketing and advertising. Dissemination of the Wheel of Five and its recommendations to the general public is enhanced by means of repeated, targeted communications via diverse media channels, social media, tools, apps, cookery books, brochures and campaigns. Important strategies include changing dietary patterns in small steps and improving food literacy. Consumers are assisted by several tools and apps to adapt the diet to their personal situation, preferences and needs (type of work, activities during leisure time, etc.). Little is known about the efficiency of FBDG on a public health level ${ }^{(70)}$. Although a consumer survey in 2017 indicated that $96 \%$ of Dutch consumers were aware of the Wheel of Five and $64 \%$ indicate to understand it (Netherlands Nutrition Centre, unpublished results), it is important to monitor the effects of such an integrated approach with food consumption survey data.

\section{Conclusion}

In conclusion, based on an optimisation model, scientific evidence, information on dietary patterns and expert knowledge, we derived FBDG for a wide range of target groups. The Wheel of Five is a key food-counselling model that can help Dutch consumers to make their diets healthier and more environmentally sustainable. 


\section{Acknowledgements}

Acknowledgements: The authors greatly acknowledge the input of experts in the field of nutrition, sustainability, behaviour and communication, dietitians from the Netherlands Organisation of Dieticians (NVD) and Dieticians Cooperation Netherlands (DCN), members of the HCNL, and fellow workers of the Netherlands Nutrition Centre and the National Institute for Public Health and the Environment. Financial support: The National Institute for Public Health and the Environment contribution to this research was funded by the Dutch Ministry of Health, Welfare and Sport. Furthermore, this research received no specific grant from any funding agency in the public, commercial or not-for-profit sectors. Conflict of interest: None. Authorship: E.B., A.P.-S., A.S., D.W. and C.V.D. were involved in formulating the research question. E.B., M.G., C.v.R., A.P.-S., A.S., D.W. and M.O. were involved in designing the study. C.v.R., I.T., M.G. and E.B.-R. performed the data management and data analyses. All authors were involved in the interpretation of the data analysis. E.B., C.v.R. and M.O. drafted the manuscript. All authors provided input on the draft manuscript and read and approved the final manuscript. Ethics of buman subject participation: Not applicable.

\section{Supplementary material}

To view supplementary material for this article, please visit https://doi.org/10.1017/S1368980019001435

\section{References}

1. GBD 2016 Risk Factors Collaborators (2017) Global, regional, and national comparative risk assessment of 84 behavioural, environmental and occupational, and metabolic risks or clusters of risks, 1990-2016: a systematic analysis for the Global Burden of Disease Study 2016. Lancet 390, 1345-1422.

2. European Food Safety Authority Panel on Dietetic Products, Nutrition, and Allergies (2010) Scientific opinion on establishing food-based dietary guidelines. EFSA J 8, 42.

3. Montagnese C, Santarpia L, Buonifacio M et al. (2015) European food-based dietary guidelines: a comparison and update. Nutrition 31, 908-915.

4. Sandstrom B (2001) A framework for food-based dietary guidelines in the European Union. Public Health Nutr $\mathbf{4}$ 293-305.

5. Reynolds CJ, Buckley JD, Weinstein P et al. (2014) Are the dietary guidelines for meat, fat, fruit and vegetable consumption appropriate for environmental sustainability? A review of the literature. Nutrients 6, 2251-2265.

6. Konde AB, Bjerselius R, Haglund L et al. (2015) Swedish Dietary Guidelines - Risk and Benefit Management Report. Livsmedelsverkets Rapportserie nr 5/2015. Uppsala: Livsmedelsverkets, National Food Agency.

7. Gonzales Fischer C \& Garnett T (2016) Plates, Pyramids and Planets; Development in National Healthy and Sustainable Dietary Guidelines: A State of Play Assessment. Rome: FAO and Oxford University.
8. Versele V \& Neven L (2017) Substantiation of the Vision on Nutrition and Sustainability. Background Document with Renewed Guidelines and Visual Representation of the Food Triangle (in Flemish). Brussels: Vlaams Instituut Gezond Leven.

9. Food and Agriculture Organization of the United Nations \& World Health Organization (1998) Preparation and Use of Food-Based Dietary Guidelines. Geneva: FAO/WHO.

10. Netherlands Nutrition Centre (2011) Guidelines Food Choices (in Dutch). The Hague: Netherlands Nutrition Centre.

11. Britten P, Marcoe K, Yamini S et al. (2006) Development of food intake patterns for the MyPyramid Food Guidance system. J Nutr Educ Behav 38, S78-92.

12. Kersting M, Alexy U \& Clausen K (2005) Using the concept of Food Based Dietary Guidelines to develop an optimized mixed diet (OMD) for German children and adolescents. J Pediatr Gastroenterol Nutr 40, 301-308.

13. Okubo H, Sasaki S, Murakami K et al. (2015) Designing optimal food intake patterns to achieve nutritional goals for Japanese adults through the use of linear programming optimization models. Nutr J 14, 57.

14. National Health and Medical Research Council (2011) $A$ Modelling System to Inform the Revison of the Australian Guide to Healthy Eating. Canberra: Commonwealth of Australia.

15. Maillot M, Vieux F, Amiot MJ et al. (2010) Individual diet modeling translates nutrient recommendations into realistic and individual-specific food choices. Am J Clin Nutr $\mathbf{9 1}$, 421-430.

16. Ferguson EL, Darmon N, Briend A et al. (2004) Food-based dietary guidelines can be developed and tested using linear programming analysis. J Nutr 134, 951-957.

17. Buttriss JL, Briend A, Darmon N et al. (2014) Diet modelling: how it can inform the development of dietary recommendations and public health policy. Nutr Bull 39, $115-125$.

18. Dantzig GB \& Thapa MN (2003) Linear Programming 2. Theory Extensions. New York: Springer.

19. Wilson N, Nghiem N, Ni Mhurchu C et al. (2013) Foods and dietary patterns that are healthy, low-cost, and environmentally sustainable: a case study of optimization modeling for New Zealand. PLoS One 8, e59648.

20. Kromhout D, Spaaij CJ, de Goede J et al. (2016) The 2015 Dutch food-based dietary guidelines. Eur J Clin Nutr 70, 869-878.

21. Health Council of the Netherlands (2014) Temporary Dietary Reference Values (in Dutch). https://www. gezondheidsraad.nl/documenten/adviezen/2015/11/04/ tijdelijke-voedingsnormen (accessed March 2018).

22. Van Rossum CTM, Fransen HP, Verkaik-Kloosterman J et al. (2011) Dutch National Food Consumption Survey 20072010: Diet of Children and Adults Aged 7 to 69 Years. RIVM-report no. 350070006. Bilthoven: National Institute for Public Health and the Environment.

23. Ocké MC, Buurma-Rethans EJM, De Boer EJ et al. (2013) Diet of Community-Dwelling Older Adults: Dutch National Food Consumption Survey Older Adults 2010-2012. RIVM-report no. 050413001/2013. Bilthoven: National Institute for Public Health and the Environment.

24. Ocké MC, Van Rossum CTM, Fransen HP et al. (2008) Dutch National Food Consumption Survey Young Children 2005/ 2006. RIVM-report no. 350070001. Bilthoven: National Institute for Public Health and the Environment.

25. de Boer EJ, Brants HAM, Beukers M et al. (2015) Diet of Moroccan, Turkish, Surinamese and Native Dutch in Amsterdam (in Dutch). RIVM report no. 2015-099. Bilthoven: National Institute for Public Health and the Environment. 
26. Health Council of the Netherlands (2011) Guidelines for a Healthy Diet: The Ecological Perspective. Den Haag: Gezondheidsraad.

27. European Food Safety Authority, Scientific Committee on Food \& Scientific Panel on Dietetic Products, Nutrition and Allergies (2006) Tolerable Upper Intake Levels for Vitamins and Minerals. Parma: EFSA.

28. National Institute for Public Health and the Environment (2013) NEVO-online version 2013/4.0. https://nevo-online.rivm.nl/ (accessed October 2015).

29. Kennis en adviescentrum voor de bakkerij (2016) Sixth National Sample Salt Content in Bread 2015 (in Dutch). In opdracht van NVB Wageningen. http://www.nedverbak.nl/nieuwsbericht. htm?nieuwsItem_WebID\%3D392\%26nieuws_WebID\%3D9 (accessed January 2016).

30. Netherlands Food and Consumer Product Safety Authority (2014) Monitoring Salt Content of Meat Replacers (in Dutch). The Hague: NVWA.

31. Health Council of the Netherlands (2001) Dietary Reference Intakes: Energy, Proteins, Fats and Digestible Carbohydrates (in Dutch). Publication no. 2001/19R. The Hague: Health Council of the Netherlands.

32. Health Council of the Netherlands (2003) Overweight and Obesity (in Dutch). Publication no. 2003/07. The Hague: Health Council of the Netherlands.

33. Schonbeck Y, Talma H, van Dommelen P et al. (2011) Increase in prevalence of overweight in Dutch children and adolescents: a comparison of nationwide growth studies in 1980, 1997 and 2009. PLoS One 6, e27608.

34. Schonbeck Y, Talma H, van Dommelen P et al. (2013) The world's tallest nation has stopped growing taller: the height of Dutch children from 1955 to 2009. Pediatr Res 73, 371-377.

35. Montgomery C, Reilly JJ, Jackson DM et al. (2004) Relation between physical activity and energy expenditure in a representative sample of young children. Am J Clin Nutr 80, 591-596.

36. Ekelund U, Yngve A, Brage S et al. (2004) Body movement and physical activity energy expenditure in children and adolescents: how to adjust for differences in body size and age. Am J Clin Nutr 79, 851-856.

37. Spadano JL, Bandini LG, Must A et al. (2005) Longitudinal changes in energy expenditure in girls from late childhood through midadolescence. Am J Clin Nutr 81, 1102-1109.

38. Brink L, Postma-Smeets A, Stafleu A et al. (2016) Guidelines Wheel of Five (in Dutch). The Hague: Netherlands Nutrition Centre.

39. Westhoek H, Lesschen JP, Rood T et al. (2014) Food choices, health and environment: effects of cutting Europe's meat and dairy intake. Glob Environ Change 26, 196-205.

40. World Cancer Research Fund \& American Institute for Cancer Research (2007) Food, Nutrition, Physical Activity and the Prevention of Cancer: A Global Perspective. Washington, DC: AICR.

41. Health Council of the Netherlands (2012) Evaluation of the Dietary Reference Values for Vitamin D (in Dutch). Publication no. 2012/15. The Hague: Health Council of the Netherlands.

42. Van Dooren C, Tyszler M, Kramer G et al. (2015) Low climate impact and high nutritional value in one shopping basket through diet optimization by linear programming. Sustainability 7, 12837.

43. Kramer GHB (2015) The Menu of Tomorrow (in Dutch). Gouda: Blonk Consultants.

44. Centraal Bureau voor de Statistiek (2016) Population to migration background (in Dutch). https://www.cbs.nl/nlnl/achtergrond/2016/47/bevolking-naar-migratieachtergrond (accessed April 2018).
45. Geurts M, Toxopeus I, Van Rossum C et al. (2016) Background Data of Reference Diets for the Guidelines of the Wheel of Five 2016 (in Dutch). Bilthoven: National Institute for Public Health and the Environment.

46. den Hartog C \& van Schaik TFSM (1953) A new way of food education (in Dutch). Voeding 14, 251.

47. European Food Safety Authority Panel on Dietetic Products, Nutrition and Allergies (2015) Scientific opinion on dietary reference values for iron. EFSA J 13, 4254.

48. Health Council of the Netherlands (2008) Towards an Optimal Use of Folic Acid (in Dutch). Publication no. 2008/02. The Hague: Health Council of the Netherlands.

49. Milieucentraal (2015) Calender of vegetables and fruit (in Dutch). https://groentefruit.milieucentraal.nl/ (accessed March 2018).

50. Montagnese C, Santarpia L, Iavarone F et al. (2017) North and South American countries food-based dietary guidelines: a comparison. Nutrition 42, 51-63.

51. Hess R, Visschers VH \& Siegrist M (2012) Effectiveness and efficiency of different shapes of food guides. J Nutr Educ Behav 44, 442-447.

52. Van Rossum C, Buurma-Rethans E, Vennemann $\mathrm{F}$ et al. (2017) Food Consumption 2012-2014 Compared with the Wheel of Five (in Dutch). MEMO-VCP 17-03. Bilthoven: National Institute for Public Health and the Environment.

53. Estruch R, Ros E, Salas-Salvado J et al. (2013) Primary prevention of cardiovascular disease with a Mediterranean diet. N Engl J Med 368, 1279-1290.

54. Public Health England (2016) The Eatwell Guide - How does it Differ to the Eatwell Plate and Why? London: Public Health England.

55. Garnett T (2011) Where are the best opportunities for reducing greenhouse gas emissions in the food system (including the food chain)? Food Policy 36, Suppl. 1, S23-S32.

56. Tilman D, Cassman KG, Matson PA et al. (2002) Agricultural sustainability and intensive production practices. Nature 418, 671-677.

57. Pauly D, Christensen V, Guénette S et al. (2002) Towards sustainability in world fisheries. Nature 418, 689-695.

58. Van Dooren C, Aiking H \& Vellinga P (2017) In search of indicators to assess the environmental impact of diets. Int $J$ Life Cycle Assess 23, 1297-1314.

59. Food and Agriculture Organization of the United Nations (2013) Food Wastage Footprint; Impacts on Natural Resources. Rome: FAO.

60. Jones $\mathrm{AD}$, Hoey L, Blesh J et al. (2016) A systematic review of the measurement of sustainable diets. Adv Nutr 7, 641-664.

61. Van de Kamp ME, Van Dooren C, Hollander A et al. (2018) Healthy diets with reduced environmental impact? The greenhouse gas emissions of various diets adhering to the Dutch food based dietary guidelines. Food Res Int 104, $14-24$.

62. Temme EH, Toxopeus IB, Kramer GF et al. (2015) Greenhouse gas emission of diets in the Netherlands and associations with food, energy and macronutrient intakes. Public Health Nutr 18, 2433-2445.

63. Macdiarmid JI, Kyle J, Horgan GW et al. (2012) Sustainable diets for the future: can we contribute to reducing greenhouse gas emissions by eating a healthy diet? Am J Clin Nutr 96, 632-639.

64. Perignon M, Masset G, Ferrari G et al. (2016) How low can dietary greenhouse gas emissions be reduced without impairing nutritional adequacy, affordability and acceptability of the diet? A modelling study to guide sustainable food choices. Public Health Nutr 19, 2662-2674. 
65. Garnett T (2006) Fruit \& Vegetables \& UK Greenhouse Gas Emissions: Exploring the Relationship; Working Paper Produced as Part of the Work of the Food Climate Research Network. Guildford: University of Surrey.

66. Mertens E, van't Veer P, Hiddink GJ et al. (2017) Operationalising the health aspects of sustainable diets: a review. Public Health Nutr 20, 739-757.

67. Van Dooren C (2018) A review of the use of linear programming to optimize diets, nutritiously, economically and environmentally. Front Nutr 5, 48.
68. Gerdessen JC \& de Vries JH (2015) Diet models with linear goal programming: impact of achievement functions. Eur J Clin Nutr 69, 1272-1278.

69. Willett W, Rockström J, Loken B et al. (2019) Food in the Anthropocene: the EAT-Lancet commission on healthy diets from sustainable food systems. Lancet 393, 447-492.

70. Brown KA, Timotijevic L, Barnett J et al. (2011) A review of consumer awareness, understanding and use of food-based dietary guidelines. BrJ Nutr 106, 15-26. 